\title{
INFLUENCE OF OPPOSITION ON OVERHEAD SMASH VELOCITY IN PADEL PLAYERS
}

\author{
Jesús Rivilla-García ${ }^{1}$, Alejandro Muñoz Moreno ${ }^{2}$, Jorge Lorenzo ${ }^{1}$, \\ Roland van den Tillaar ${ }^{3}$, and Archit Navandar ${ }^{1,4}$ \\ ${ }^{1}$ Sports Department, Universidad Politécnica de Madrid, Madrid, Spain \\ ${ }^{2}$ Faculty of Health Sciences, Universidad Francisco de Vitoria (UFV), Madrid, Spain \\ ${ }^{3}$ Department of Sport Science and Physical Education, Nord University, Levanger, Norway \\ ${ }^{4}$ Faculty of Sport Sciences, Universidad Europea de Madrid, Madrid, Spain
}

Original scientific paper

DOI: $10.26582 / \mathrm{k} .51 .2 .6$

\begin{abstract}
:
Although it is well established that velocity of execution is an important performance factor in ball sports and the presence of opposition influences it, there has been no research done to date on ball velocity in padel shots. The overhead smash is one of the most successful shots in this sport, and the present study aimed to study the effect of opposition on smash performance in semi-professional and amateur padel players. Forty-four semi-professional $(\mathrm{n}=14)$ and amateur $(\mathrm{n}=30)$ players volunteered to participate in this study. The overhead smash velocity was recorded for both groups of players with and without opposition using a radar gun. Ball velocity decreased in both groups of players in the presence of opposition (from 133.1 \pm 8.2 $\mathrm{km} \cdot \mathrm{h}^{-1}$ to $120.72 \pm 9.8 \mathrm{~km} \cdot \mathrm{h}^{-1}$ in semi-professional players; and from $124.6 \pm 9.2 \mathrm{~km} \cdot \mathrm{h}^{-1}$ to $104.5 \pm 10.0 \mathrm{~km} \cdot \mathrm{h}^{-1}$ in amateurs, $\mathrm{p}<.001)$. Although the semi-professional players achieved a greater velocity in both situations $(\mathrm{p}<.001)$ compared to amateurs, the reduction of velocity in the presence of opposition was greater in the amateurs $(\mathrm{p}<.001)$. The greater velocities for the semi-professional padel players could be attributed to a technical and tactical superiority due to their greater experience and higher level of competition. Simulating conditions of opposition could help reduce the velocity-precision trade-off, helping the players increase their overhead smash velocities.
\end{abstract}

Key words: ball velocity, racquet sports, paddle tennis, performance modification, performance analysis

\section{Introduction}

Padel is a racquet sport that is widely popular in Spanish speaking countries. In Spain, $46.2 \%$ of the population over the age of 15 play it at least once a week, and $19.5 \%$ play it every day (VillenaSerrano, Castro-Lopez, Lara-Sánchez, \& CachonZagalaz, 2016). Padel has experienced a significant growth recently, as can be seen by an increase in the number of participants from 1.19 million in 2010 to 4.17 million in 2015 (Courel-Ibáñez, SánchezAlcaraz, García-Benítez, \& Echegaray, 2017a) and seen an increase in federative licences from around 40,000 to 56,000 in the last four years, from 2012 to 2015 (MECD, 2016; Villena-Serrano, et al., 2016). This increase could be due to moderate physiological demands of the sport, a reduced playing field and simple rules (Lasaga, 2011; Sánchez-Alcaraz, 2014). The sport is played in pairs on a $20 \mathrm{~m} \mathrm{x}$ $10 \mathrm{~m}$ court divided in two areas by a net where the enclosing walls are a part of the game.
Investigations in padel are scarce, in spite of its popularity, although there has been a notable increase of them in the last few years (SánchezAlcaraz, Cañas, \& Courel-Ibáñez, 2015; SanchezAlcaraz, Courel-Ibanez, \& Canas, 2018; Villena Serrano, Zagalaz Sánchez, Castro López, \& Cachón Zagalaz, 2017). Studies have focused on the health benefits and risks and fitness condition related to the sport (Courel-Ibáñez, et al., 2018; De Prado, Sánchez-Alcaraz, García-Navarro, \& Barruenzo, 2013; Navarro, et al., 2013; Priego, et al., 2013); physiological demands (Carrasco, Romero, Sañudo, \& De Hoyo, 2011; Castillo-Rodríguez, Hernández-Mendo, \& Fernández-García, 2014; Sánchez-Alcaraz, et al., 2015); match activity profile and temporal structure (Courel-Ibáñez, Sánchez-Alcaraz, \& Cañas, 2017b; Courel-Ibáñez, Sánchez-Alcaraz, \& Muñoz-Marín, 2019; GarcíaBenítez, Courel-Ibáñez, Perez-Bilbao, \& Felipe, 2018; Sanchez-Alcaraz, et al., 2018; Torres-Luque, Sánchez-Pay, Fernández-García, \& Palao, 2014). 
Being a racquet sport, studies have compared the physiological, physical and tactical demands in padel to those in tennis, squash and badminton. Studies have shown that the physiological demands are lower than of other racquet sports such squash or badminton (Sánchez-Alcaraz, 2014), but the volume of oxygen consumed by players is similar to that in tennis both in peak and relative values (Carrasco, et al., 2011; Hoyo, Sañudo, \& Carrasco, 2007). Comparing on-court movements, there is a predominance of lateral movements (52\%) over forward and backward movements in the sport (Priego, et al., 2013), differing from those in tennis (Pieper, Exler, \& Weber, 2007).

In the specific area of performance analysis in padel, there are some studies with the aim to improve the game and training plan for coaches and players (Priego, et al., 2013; Sánchez-Alcaraz, 2014). There are studies analysing the success of a rally in relation to its duration (Courel-Ibáñez, et al., 2017b) and other investigations about the most common types of shots in each area of the court. Around $68 \%$ of the shots in padel are direct, that is they occur after the ball bounces off the ground: volley, forehand, backhand, lob and smash (Priego, et al., 2013). Among them, players tend to play more volleys while at the net (Muñoz-Marín, et al., 2017). Overhead smashes are the most successful shots during a match along with cross court lobs (Carrasco, et al., 2011; Priego, et al., 2013). They are played from the centre to maintain a positional advantage and increase chances of winning a point (Courel-Ibáñez, et al., 2019; Lupo, et al., 2018). The success of the smash as a winner depends, amongst other factors, on velocity and accuracy with which it is executed.

Velocity, along with accuracy, is a key determinant of the success of the offensive shots as proven in other sports (Bayios, Anastasopoulou, Sioudris, \& Boudolos, 2001; DeRenne, Ho, \& Murphy, 2001; Freeston \& Rooney, 2008; Gorostiaga, Granados, Ibanez, \& Izquierdo, 2005; Van Den Tillaar \& Marques, 2013). The velocity of execution relies on technique, ensuring that there is a continuum of coordination from the proximal (upper arm) to the distal segment (racquet) (Knudson, 2007), physical characteristics of the player (the application of a greater moment of force by the transfer of angular momentum from the player to the ball; Bartlett, 2007; Knudson, 2007), and the tactics employed (Bartlett, 2007). The on-court presence of an opponent influences where the shot is played in order to be successful as the accuracy of the shot played becomes important. Theoretically, a velocity-accuracy trade-off exists, that is, when focusing on accuracy, velocity would decrease (Fitts, 1954). Previous studies in other swinging sports such as soccer, handball, and water polo have shown that velocity decreases in the presence of opposition in elite and amateur players (Rivilla-Garcia, Calvo, \& Van Den Tillaar, 2016; Rivilla-Garcia, Grande, Sampedro, \& Van Den Tillaar, 2011; Van der Wende, 2005; Vila, et al., 2009). In padel, the player must execute the smash against two opponents across the net, which could influence both the velocity, the placement and the technique of the shot. However, it is not known how the presence of opposition influences smash velocity. Furthermore, it is unknown if a different skill level could affect ball velocity differently.

Therefore, the aim of the study was to investigate the effect of opposition on smash performance in semi-professional and amateur padel players. The hypotheses were that the opposition had a negative effect upon smash performance and this effect would be greater in amateur players than in semiprofessional players due to a difference in skill level.

\section{Methods}

\section{Participants}

Forty-four male padel players volunteered to participate in the study. The sample was composed of semi-professional ( $\mathrm{n}=14$; age: $29.2 \pm 3.9$ years; body height: $185 \pm 9.8 \mathrm{~cm}$; body weight: $86.7 \pm 8.6$ $\mathrm{kg}$; experience: $9.7 \pm 4.6$ years $)$ and amateur $(\mathrm{n}=30$; age: $23.2 \pm 4.2$ years; body height: $178 \pm 7.5 \mathrm{~cm}$; body weight: $82.2 \pm 6.9 \mathrm{~kg}$; experience: $5.8 \pm 3.1$ years) players. The semi-professional players had federal licences, and in the previous season had competed in at least six national tournaments and in at least one preliminary phase of the professional padel circuit, World Padel Tour. On the other hand, the amateur players had at least three years of experience and practices in the sport for an average time of three hours per week. All the participants signed an informed consent where they were informed about the protocol to be followed as well as the potential risks involved. The university ethics committee had approved the procedure and the study followed the typical ethical standards of investigation in physical activities and sport.

\section{Material}

Tests were performed in an indoor padel facility certified by the F.E.P (Federación Española de Padel - Spanish Padel Federation), preserving lighting, wind, temperature and sunlight conditions throughout data collection. Head Padel Pro, the official balls of the World Padel Tour were used in the study. The velocity of the ball was measured using a radar (StalkerPro, AppliedConcepts, Inc, Plano, USA) at $100 \mathrm{~Hz}$ with an accuracy of $0.045 \mathrm{~m} \cdot \mathrm{s}^{-1}$. The radar was placed behind the player who executed the smash. To analyse the movements of the opponents as well as the technique and the adequate conditions of the player, a video camera was located lateral to the ball hit zone. 


\section{Procedures}

The highest velocity of the ball during a smash (in $\mathrm{km} \cdot \mathrm{h}^{-1}$ ) was evaluated in two different situations: a) velocity without the opposition, and b) velocity with the real opposition, in other words, with two players in front trying to defend each smash. Each test was performed with at least 24 hours of active rest or 48 hours after a competition.

The players first performed a general warmup, which included running, mobility exercises at a low intensity and dynamic flexibility exercises. This was followed by specific exercises focusing on shoulder stability, mobility and strength. Finally, a padel specific warm-up was carried out, where the participants performed smashes similar to those that were to be performed during the test for a duration of ten minutes.

The test protocol was shown to each of the players so that they were familiarised with the conditions. The instructions were common for both tests and for all the players: they had to smash the ball at the fastest possible velocity such that the ball returned to the participant's side of the court after it had bounced off the rival's court and back wall.

In order to increase the ecological validity, the player was positioned on the centre line of his court at a distance of two meters from the net - distance at which net play usually takes place (Figure 1). The researcher then played a lob shot to each participant so that the participant could smash the ball in between two lines placed at 2 and 3 meters from the net (Figure 1).

Players carried out the tests under the following conditions: 1) without the opposition, where the smash was executed without players on the opposite court; and 2) with the opposition, where two players were on the opposite court, who started at the end of the court and were free to move around on the court. In both situations an observer analysed the smash using a laterally placed high definition camera.

Each participant performed two rounds of smashes, each consisting of four smashes with the opposition and four without it. The first round

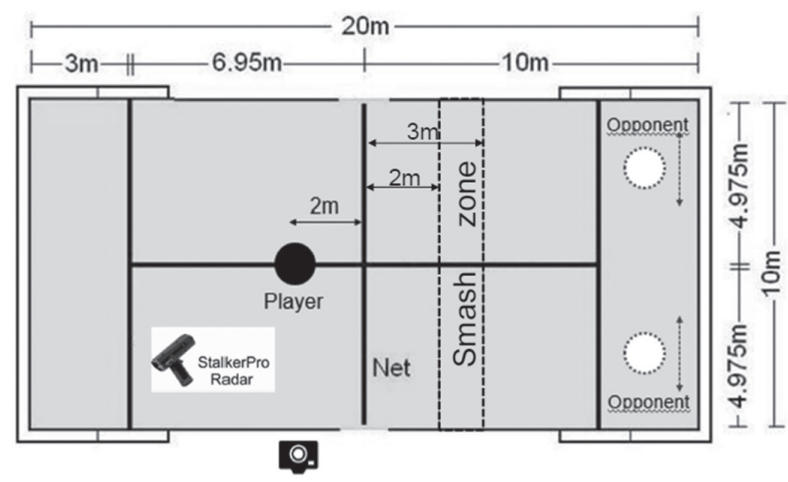

Figure 1. Experimental set up showing the smash target, the position of opponents and the radar gun. started with the situation without the opposition and moved to one with the opposition, while in the second round, the participant faced a situation with the opposition first and moved to one without it. This was done to ensure that fatigue did not affect any possible differences. There was a rest period of 10-15 seconds between smashes, and, if the participants had to perform another extra smash due to a failure in the data retrieval, another round of smashes was performed after a minimum recovery period of two minutes. No player performed more than 20 smashes overall, thus avoiding fatigue due to the accumulation of explosive actions (Gorostiaga, et al., 2005; Gutiérrez, Garcia, Parraga, \& Rojas, 2006; Rivilla-Garcia, et al., 2011). With the objective of motivating the players, they were informed about the ball velocity reached after each of the shots. The peak values of ball velocities were used for the analysis.

\section{Statistical analysis}

The velocities recorded with the opponents and without them were collected and subjected to the Kolmogorov-Smirnov test for normality, which gave a non-significant result indicating the normal distribution of the data. To compare the effects of the opposition on smash performance of semiprofessional and amateur padel players, the smash velocities were compared with a $2 \times 2$ analysis of variance (ANOVA). The presence of the opponents (with and without the opposition) and the group to which the participants belonged (semi-professional and amateur players) were considered as independent variables. Post-hoc tests with Bonferroni correction were performed to compare intergroup differences.

The effect size was evaluated with $\eta_{\mathrm{p}}^{2}$ (Eta partial squared), where $0.01<\eta^{2}<0.06$ constituted a small effect, a medium effect when $0.06<\eta^{2}<0.14$ and a large effect when $\eta^{2}>0.14$ (Cohen, 1988). The reliability of the performance tests was evaluated by calculating the test-retest reliability. The level of significance was set at $\alpha=.05$. The statistical analysis was performed using SPSS version 23.0 (IBM Corp. Released 2015. IBM SPSS Statistics for Windows, Version 23.0. Armonk, NY: IBM Corp).

\section{Results}

As expected, a significantly higher smash velocity was found for the semi-professional players than the amateur players in both conditions: with and without the opposition $\left(\mathrm{F}=42.6, \mathrm{p}<.001, \eta^{2}=0.50\right.$, Figure 2). Furthermore, smash performance decreased for both groups when the opposition was involved ( $\mathrm{F}=754, \mathrm{p}<.001, \eta^{2}=0.94$, Figure 2$)$. However, the effect of the opposition on smash performance was significantly larger in the amateur players $(-16 \%)$ than in the semi-professional (-9.2\%) players $(t=7.8, p<.001$, Figure 2$)$. 
Table 1. Peak velocity $(M \pm S D)$ of the overhead smash $\left(\mathrm{km} \cdot \mathrm{h}^{-1}\right)$ for the semi-professional and amateur padel tennis players

\begin{tabular}{lccccc}
\hline Level & $\mathrm{n}$ & $\begin{array}{c}\text { Velocity without the } \\
\text { opposition }\left(\mathrm{km} \cdot \mathrm{h}^{-1}\right)\end{array}$ & $\begin{array}{c}\text { Velocity with the } \\
\text { opposition }\left(\mathrm{km} \cdot \mathrm{h}^{-1}\right)\end{array}$ & $\begin{array}{c}\text { Total difference } \\
\left(\mathrm{km} \cdot \mathrm{h}^{-1}\right)\end{array}$ & $\begin{array}{c}\text { Percentage } \\
\text { decrease } \\
(\%)\end{array}$ \\
\hline $\begin{array}{l}\text { Semi-professional } \\
\text { Amateur }\end{array}$ & 14 & $133.12 \pm 3.74$ & $120.81 \pm 3.01$ & $12.31 \pm 2.36^{*}$ & 9.25 \\
$\begin{array}{l}\text { Inter-group difference } \\
(\mathrm{km} / \mathrm{h})\end{array}$ & 30 & $124.55 \pm 5.17$ & $104.55 \pm 4.64$ & $20.00 \pm 4.08^{*}$ & 16.06 \\
$\begin{array}{l}\text { Percentage of } \\
\text { difference }(\%)\end{array}$ & $8.57 \pm 8.56^{*}$ & $16.18 \pm 9.88^{*}$ & & \\
\hline
\end{tabular}

* indicates a significant difference for this variable at $p<.05$.

Note. $\%$ decrease $=$ (velocity without the opposition - velocity with the opposition) / velocity without the opposition * 100; \% difference $=($ velocity semi-professional - velocity amateur $) /$ velocity semi-professional * 100.

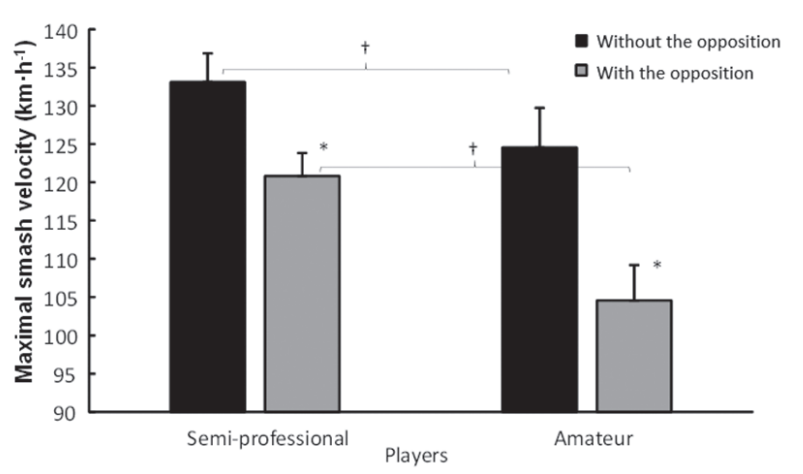

Note. $\dagger$ indicates a significant difference $(\mathrm{p}<.05)$ between the semi-professional and amateur players; $*$ indicates a significant difference between the groups with and without the opposition.

Figure 2. Maximal smash velocity $( \pm S D)$ achieved by the semiprofessional and amateur padel tennis players.

\section{Discussion and conclusions}

In this paper, the influence of the opposition on smash velocity in amateur and semi-professional padel players was studied. Participants had to smash the ball that was lobbed to them while they were at the centre of the court, and ball velocities of participants were recorded using a radar gun. The results found that the presence of the opposition had a negative effect upon smash performance, reducing the ball velocity as a consequence and its effect was greater in the amateur players, confirming the hypothesis presented in the current study. This shows the influence of cognitive factors over specific biomechanical patterns in the striking velocity of a direct smash, and that this phenomenon affects amateur players more than the semiprofessionals.

These results where velocity has been reduced in the presence of the opposition may be caused by the requirements of a greater precision (Fitts, 1954) and an increase in visual stimuli (Desimone \& Duncan, 1995). In this study, the athletes were specifically asked to ensure that the ball returned to their own court after it had bounced off the back wall. One must consider that in padel, unlike most of the other racquet sports except squash, the players can return the ball after it rebounds off the back wall after having previously bounced in their court (Courel-Ibáñez, et al., 2019). The presence of the two opposing players, who were free to move over their court, ensured that the players had to execute the smash with a greater precision. The players were required to devote a greater attention to the presence and movement of the opposing players while simultaneously trying to focus on a perfect execution of the smash. The area available to play the shot reduces, and one must be precise in both the placement and direction in the shot execution. The amateurs appeared to be more affected by the increased visual stimuli and the velocityprecision trade-off (Fitts, 1954) was predominant in their case, while the semi-professional players were better accustomed to such scenarios.

Such a decrease in ball velocity in the presence of the opposition has been previously researched in other sports (Rivilla-Garcia, et al., 2011; Van der Wende, 2005; Vila, et al., 2009). The greater smash velocity in semi-professional players could be attributed to their technical and tactical superiority, who played at a higher level of competition and trained more often than the amateur players. Although the biomechanical pattern was not studied here, similar results in the overhead smash were obtained in other racquet sports. In badminton, a more efficient stretch-shortening cycle of the highly skilled players has resulted in the linear increase of smash velocity with skill level (Phomsoupha \& Laffaye, 2014). This permitted more skilled players to increase the mechanical impulse by the production of higher forces in the shortest amount of time by a high acceleration of the distal joint finally resulting in a greater shuttle velocity (Phomsoupha \& Laffaye, 2014). Similarly, a more efficient biomechanical pattern in the smash of the semi-professional padel players could explain the differences in ball velocities between the levels. The greater experience of the semi-professionals 
permitted them to be more aware of different situations, which allowed them not only to anticipate the movements of the opposition, but also to make the right decisions (Singer \& Janelle, 1999). Previous studies have spoken about how the instruction (Van den Tillaar \& Ulvik, 2014) and increasing visual stimuli (Desimone \& Duncan, 1995; Rivilla-Garcia, et al., 2011) can influence the biomechanical pattern in swinging sports, a phenomenon seen in padel as well. In amateurs, the velocity-precision tradeoff possibly caused a change in their technique that resulted in a lower ball velocity. As previously stated, a greater ball velocity is a crucial aspect of success.

Smash velocity partly depends on the physical characteristics of the player and the racquet used, but certain changes to the way the players train could bring about an increased velocity in the overhead smash in the presence of the opposition. Working on training exercises that simulate the presence of the opposition, such as increasing the visual stimuli available, or restricting the area and direction to where the shot can be placed, could lend a direct transfer of skill. This would help semi- professional and amateur players alike, increasing their possibilities of striking a winner.

It is important to state that this study was the first to study the velocity of any padel stroke. However, the study had its limitations: the velocity, height and distance of the lob played prior to the smash was not controlled with an exact precision given that it was a researcher, and not a ball machine, that lobbed the ball. Future studies could work to correct this. Another limitation was that a biomechanical analysis of the smash technique was not carried out. Such a study would not only identify differences between the semi-professional and amateur players, but would also help to identify the change in technique that occurs in the presence of the opposition, giving coaches and players valuable feedback that could be incorporated in the training to improve performance. The demands of the game of padel are unique and the growing popularity of the sport require more investigations in the future in this line. A study of the kinematics of the padel strokes, especially analysis of the overhead smash could provide more information.

\section{References}

Bartlett, R. (2007). Introduction to sports biomechanics: Analysing human movement patterns ( $2^{\text {nd }}$ ed.). London, New York: Routledge.

Bayios, I.A., Anastasopoulou, E.M., Sioudris, D.S., \& Boudolos, K.D. (2001). Relationship between isokinetic strength of the internal and external shoulder rotators and ball velocity in team handball. Journal of Sports Medicine and Physical Fitness, 41(2), 229-235.

Carrasco, L., Romero, S., Sañudo, B., \& De Hoyo, M. (2011). Game analysis and energy requirements of paddle tennis competition. Science and Sports, 26(6), 338-344.

Castillo-Rodríguez, A., Hernández-Mendo, A., \& Fernández-García, J.C. (2014). Physical and physiological responses in paddle tennis competition. International Journal of Performance Analysis in Sport, 14(2), 524-534.

Cohen, J. (1988). Statistical power analysis for the behavioral sciences $\left(2^{\text {nd }}\right.$ ed.). Mahwah, NJ: Lawrence Erlbaum Associates.

Courel-Ibáñez, J., Cordero, J., Muñoz, D., Sánchez-Alcaraz, B., Grijota, F., \& Robles, M. (2018). Fitness benefits of padel practice in middle-aged adult women. Science and Sports, 33(5), 291-298.

Courel-Ibáñez, J., Sánchez-Alcaraz, B., \& Cañas, J. (2017). Game performance and length of rally in professional padel players. Journal of Human Kinetics, 55(1), 161-169.

Courel-Ibáñez, J., Sánchez-Alcaraz, B., García-Benítez, S., \& Echegaray, M. (2017). Evolución del pádel en España en función del género y edad de los practicantes. [Evolution of padel in Spain according to the practitioners' gender and age. In Spanish.]. Cultura Ciencia Deporte, 12(34), 39-46. doi: 10.12800/ccd

Courel-Ibáñez, J., Sánchez-Alcaraz, B., \& Muñoz-Marín, D. (2019). Exploring game dynamics in padel. Implications for assessment and training. Journal of Strength and Conditioning Research, 33(7), 1971-1977.

De Prado, F., Sánchez-Alcaraz, B.J., García-Navarro, J.N., \& Barruenzo, A. (2013). Prevención de lesiones en pádel. [Injury prevention in padel. In Spanish.] Trances, 6(4), 175-188.

DeRenne, C., Ho, K.W., \& Murphy, J.C. (2001). Effects of general, special, and specific resistance training on throwing velocity in baseball: A brief review. Journal of Strength and Conditioning Research, 15(1), 148-156.

Desimone, R., \& Duncan, J. (1995). Neural mechanisms of selective visual attention. Annual Review of Neuroscience, 18, 193-222.

Fitts, P.M. (1954). The information capacity of the human motor system in controlling the amplitude of movement. Journal of Experimental Psychology, 47, 381-391. 
Freeston, J., \& Rooney, K. (2008). Progressive velocity throwing training increases velocity without detriment to accuracy in sub-elite cricket players: A randomized controlled trial. European Journal of Sport Science, 8(6), 373-378.

García-Benítez, S., Courel-Ibáñez, J., Perez-Bilbao, T., \& Felipe, J. (2018). Game responses during young padel match play: Age and sex comparisons. Journal of Strength and Conditioning Research, 32(4), 1144-1149.

Gorostiaga, E. M., Granados, C., Ibanez, J., \& Izquierdo, M. (2005). Differences in physical fitness and throwing velocity among elite and amateur male handball players. International Journal of Sports Medicine, 26(3), $225-232$.

Gutiérrez, M., Garcia, P.L., Parraga, J., \& Rojas, F.J. (2006). Effect of opposition on the handball jump shot. Journal of Human Movement Studies, 51, 257-275.

Hoyo, M., Sañudo, B., \& Carrasco, L. (2007). Demandas fisiológicas de la competición en pádel. [Physiological demands of competitions in padel. In Spanish.] Revista Internacional de Ciencias del Deporte, 8(3), 53-58.

Knudson, D. (2007). Fundamentals of biomechanics. Springer Science \& Business Media.

Lasaga, M.J. (2011). Estudio social y metodológico del pádel desde la percepción de técnicos y jugadores: una apuesta educativa. [A social and methodological study of padel from the perception of coaches and players: An educational approach. In Spanish.] (Doctoral dissertation, Universidad de Sevilla). Sevilla: Faculty of Physical Education and Sports.

Lupo, C., Condello, G., Courel-Ibáñez, J., Gallo, C., Conte, D., \& Tessitore, A. (2018). Effect of gender and match outcome on professional padel competition. RICYDE. Revista Internacional de Ciencias del Deporte, 14(1), $29-41$.

MECD. (2016). Anuario de Estadísticas Deportivas 2016. [Annual Sports Statistics. In Spanish.] Madrid: Ministerio de Educación, Cultura y Deporte. Retrieved September 12, 2017 from http://www.csd.gob.es/csd/estaticos/ documentacion/Anuario_de_Estadisticas_Deportivas_2016\%20(2).pdf

Muñoz-Marín, D., Sánchez-Alcaraz, B.J., Courel-Ibáñez, J., Díaz, J., Julián, A., \& Muñoz-Jiménez, J. (2017). Diferencias en las acciones de subida a la red en pádel entre jugadores profesionales y avanzados. [Differences in actions of net play in padel between professional and advanced players. In Spanish.] Journal of Sport and Health Research, 9(2), 223-232.

Navarro, E., Albaladejo, R., Villanueva, R., García, C., Majón, R., \& Hernández, J.V. (2013). Estudio epidemiológico de las lesiones en el deporte de ocio: Parte II: Pádel. [Epidemiological study of injuries in recreational sports: Part II: Padel. In Spanish.] Madrid: Fundación MAPFRE.

Phomsoupha, M., \& Laffaye, G. (2014). Shuttlecock velocity during a smash stroke in badminton evolves linearly with skill level. Computer Methods in Biomechanics and Biomedical Engineering, 17(Supp1), 140-141. doi:10.1080 $/ 10255842.2014 .931550$

Pieper, S., Exler, T., \& Weber, K. (2007). Running speed loads on clay and hard courts in world class tennis. Journal of Medicine and Science in Tennis, 12(2), 14-17.

Priego, J.I., Olaso, J., Llanna, S., Pérez, P., González, J.C., \& Sanchís, M. (2013). Pádel: A quantitative study of the shots and movements in the high-performance. Journal of Human Sport and Exercise, 8(4), 925-931.

Rivilla-Garcia, J., Calvo, J., \& Van Den Tillaar, R. (2016). Comparison of throwing velocity between first and second offensive line handball players. Kinesiologia Slovenica, 22(3), 5.

Rivilla-Garcia, J., Grande, I., Sampedro, J., \& Van Den Tillaar, R. (2011). Influence of opposition on ball velocity in the handball jump throw. Journal of Sports Science and Medicine, 10, 534-539.

Sánchez-Alcaraz, B. (2014). Diferencias en las acciones de juego y la estructura temporal entre el pádel masculino $\mathrm{y}$ femenino profesional. [Differences in gameplay actions and temporal structure between male and female professional padel players. In Spanish.] Acción Motriz, 12, 17-22.

Sánchez-Alcaraz, B., Cañas, J., \& Courel-Ibáñez, J. (2015). Análisis de la investigación científica en pádel. [Analysis of scientific research in padel. In Spanish.] AGON Revista International Journal of Sport Sciences, 5(1), 44-54.

Sanchez-Alcaraz, B., Courel-Ibanez, J., \& Canas, J. (2018). Temporal structure, court movements and game actions in padel: A systematic review. Retos-Nuevas Tendencias en Educacion Fisica Deporte y Recreacion, 33, 308-312.

Singer, R.N., \& Janelle, C.M. (1999). Determining sport expertise: From genes to supremes. International Journal of Sport Psychology, 30, 117-150.

Torres-Luque, G., Sánchez-Pay, A., Fernández-García, Á., \& Palao, J. (2014). Características de la estructura temporal en tenis. Una revisión. [Characteristics of the temporal structure in tennis. A Revision. In Spanish.] Journal of Sport and Health Research, 6(2), 117-128.

Van Den Tillaar, R., \& Marques, M.C. (2013). Effect of different training workload on overhead throwing performance with different weighted balls. Journal of Strength and Conditioning Research, 27, 1196-1201.

Van den Tillaar, R., \& Ulvik, A. (2014). Influence of instruction on velocity and accuracy in soccer kicking of experienced soccer players. Journal of Motor Behavior, 46(5), 287-291.

Van der Wende, K. (2005). The effects of game specific task constraints on the outcome of the water polo shot. (Doctoral dissertation, Auckland University of Technology). New Zealand, Auckland.

Vila, H., Ferragut, C., Argudo, F.M., Abraldes, J.A., Rodríguez, N., \& Alacid, F. (2009). Relación entre parámetros antropométricos y la velocidad de lanzamiento en jugadores de waterpolo. [Relation between anthropometric parameters and throwing velocity in waterpolo players. In Spanish.] Journal of Human Sport and Exercise, $4(1), 62-74$. 
Villena-Serrano, M., Castro-Lopez, R., Lara-Sánchez, A., \& Cachon-Zagalaz, J. (2016). A systematic review of the characteristics and impact of paddle tennis in Spain. Apunts: Educación Física y Deportes, 126, 7-22.

Villena Serrano, M., Zagalaz Sánchez, M.L., Castro López, R., \& Cachón Zagalaz, J. (2017). El pádel. Revisión sistemática de la base de datos TESEO (Ministerio de Educación Español). [Padel. A systematic review of the Spanish Education Ministry's TESEO database. In Spanish.] Sportis: Revista Técnico-Científica del Deporte Escolar, Educación Física y Psicomotricidad, 3(2), 375-387.

Submitted: September 20, 2017

Accepted: February 8, 2019

Published Online First: November 12, 2019

Correspondence to:

Archit Navandar, Ph.D.

Faculty of Sport Sciences, Universidad Europea de Madrid

Calle Tajo s/n, 28670 Villaviciosa de Odón, Madrid, Spain

Phone: +34-91 2113501

E-mail: archit.navandar@universidadeuropea.es 